\title{
SOME CONSIDERATIONS ON THE SALT CONTENT OF FRESH AND OLD OX CORNEAE
}

\author{
BY \\ Hugh DaVson \\ From the Ophthalmological Research Unit (Medical Research \\ Council), Institute of Ophthalmology, London
}

THE transparency of the cornea is closely connected with its watercontent (Fischer, 1933; Kinsey and Cogan, 1942); one of the factors determining the water-content of the tissue must be the osmotic forces operating between it and its surrounding fluids, in this case the tears and aqueous humour; and these are of course indicated by the relative concentrations of salts in the tissue and fluids. It is therefore of considerable interest to determine with precision the normal concentrations of osmotically important ions in the fresh tissue and to compare them with those in older and more heavily hydrated corneae.

\section{METHODS}

The eyes from freshly slaughtered oxen -were brought to the laboratory in an ice-cold container. Water-contents were determined by measuring the loss in weight after about 16 hours at $105^{\circ}$. Chloride was estimated by Van Slyke and Sendroy's (1923) method, modified by filtering off the AgCl precipitate through an asbestos filter before titrating the excess of $\mathrm{AgNO}_{3}$ with $\mathrm{KCNS}$. For sodium and potassium the wet-ashing technique with $\mathrm{HNO}_{3}$ plus a few drops of $\mathrm{H}_{2} \mathrm{SO}_{4}$, described by Davson (1939), was employed; the Barber-Kolthoff (1928) and Kramer (1920) methods were applied to the strongly acid ashed residues. Blank runs showed that under these conditions phosphate is not precipitated by the Uranyl-Zinc acetate reagent. Since analyses were generally carried out as single determinations of whole corneae there were no duplicate determinations to give an estimate of likely errors in the chemical work; however, the methods applied have been used for many years in this laboratory with a precision well within a one per cent. error.

\section{RESUlts}

\section{The Normal Relationship}

The important ions determinable with accuracy are sodium, potassium and chloride; the quantities of these ions in one $\mathrm{kg}$. of corneal tissue are presented in Table I; for comparison the values for the aqueous humour are shown in the same table. Before any deductions may be drawn from the comparative ionic contents of cornea and aqueous humour, however, we must express the figures in comparable units. At first thought it might be considered sufficient to express the figures simply as so many millimoles per $\mathrm{kg}$. of water, but a further correction is necessary for the corneal figures for the following reason. We are concerned with the osmotic relationships between the aqueous 
humour on the one hand and the fluid from which it is separated by the corneal endothelium. That is, we are concerned with the extra-cellular matrix of the cornea; and since a part of the tissue is made up of cellular elements, we must deduct their contribution to the apparent concentration in the whole cornea. In Table II only the first correction has been made, the results being converted into millimoles per $\mathrm{kg}$. of water. The non-cellular water is calculated on the following basis. The concentration of potassium in the cornea is 23.4 millimoles per $\mathrm{kg}$. of cornea, or 29.4 millimoles per $\mathrm{kg}$. of water; it is a fair assumption that the

\section{TABLE I}

Salt content of cornea and aqueous humour in mmoles $/ \mathrm{kg}$. cornea

(The figures presented here for corneal sodium and chloride are derived from 35 eyes; for potassium 46 eyes, and for water-content 87 eyes. Standard errors are indicated.)

\begin{tabular}{|c|c|c|c|c|}
\hline & Sodium & Potassium & Chloride & $\begin{array}{l}\text { Water } \\
\text { per cent. }\end{array}$ \\
\hline Cornea & $115 \pm 0.7$ & $23.4 \pm 0.8$ & $79 \cdot 6 \pm 1 \cdot 2$ & $77.9 \pm 0.3$ \\
\hline Aqueous & $148 \pm 0.8$ & $7.0 \pm 0.4$ & $123 \pm 2 \cdot 2$ & 99 \\
\hline
\end{tabular}

TABLE II

Salt content of cornea and aqueous humour in mmoles $/ \mathrm{kg} . \mathrm{H}_{2} \mathrm{O}$

\begin{tabular}{c|c|c|c|c}
\hline & Sodium & Potassium & Chloride & $\begin{array}{c}\text { Water } \\
\text { per cent. }\end{array}$ \\
\hline $\begin{array}{c}\text { Cornea } \\
\text { Aqueous }\end{array}$ & 147.2 & 29.4 & 99.6 & $77 \cdot 9$ \\
149.5 & $7 \cdot 1$ & 124 & 99 \\
\hline
\end{tabular}

high concentration in comparison with that in the aqueous humour or plasma is due to its accumulation within the cellular units of the cornea. If we assume that the concentration in the non-cellular water is the same as in plasma, i.e., 6 to 7 millimoles $/ \mathrm{kg} . \mathrm{H}_{2} \mathrm{O}$; and that the concentration in the cellular water is 165 millimoles $/ \mathrm{kg} . \mathrm{H}_{2} \mathrm{O}$, we can calculate how much cellular water is present to give a bulk concentration in the whole cornea of 23.4 millimoles per_kg. The calculation indicates that some 15 per cent. of the water in the cornea is intra-cellular. In Table III the figures have been expressed in millimoles of ion/kg: of 
TABLE III

Salt content of corneal extra-cellular fluid and of aqueous humour in mmoles $/ \mathrm{kg} . \mathrm{H}_{2} \mathrm{O}$

\begin{tabular}{cc|c|c|c|c|c}
\hline & & Sodium & Potassium & Chloride & Bicarbonate & . Total \\
\hline Cornea & $\ldots$ & 173 & 6.5 & 120 & 35 & 334.5 \\
Aqueous & $\ldots$ & $149: 5$ & $7 \cdot 1$ & 124 & 36 & 316.6 \\
\hline
\end{tabular}

extra-cellular water; from these we see that the concentration of sodium is some 15 per cent. higher in the corneal extra-cellular water than in the aqueous humour, whilst the chloride concentration is rather less in the cornea. The demands of electrical neutrality require that the number of positive ions in the aqueous humour be equal to the number of negative ions; this necessitates that the bicarbonate concentration should be 36 millimoles $/ \mathrm{kg}$. $\mathrm{H}_{2} \mathrm{O}$ if allowance is made for the calcium and magnesium present. In the cornea, even after allowing a proportional amount of bicarbonate, there is an anion deficit of about 30 millimoles; and it is reasonable to suppose that this is accounted for by the collagen and hyaluronic acid anions. Qualitatively we may say that the ionic distribution may be represented by the scheme :-

\begin{tabular}{l|l}
\multicolumn{1}{c|}{ Cornea } & \multicolumn{1}{c}{ Aqueous } \\
& $\mathrm{NaCl}$ \\
$\mathrm{NaCl}$ & $\mathrm{NaHCO}_{3}$ \\
$\mathrm{NaHCO}$ &
\end{tabular}

where cations other than sodium are ignored and $\mathrm{X}$ refers to colloidal anions. The total estimated concentration of ions is 334.5 millimoles $/ \mathrm{kg} . \mathrm{H}_{2} \mathrm{O}$; and since that for the aqueous is $316 \cdot 6$ millimoles $/ \mathrm{kg}$. $\mathrm{H}_{2} \mathrm{O}$, the results suggest that the osmotic pressure of the extra-cellular fluid is greater than that of the aqueous humour. As a possibility this, of course, cannot be put out of court, especially in view of the continued evaporation from the corneal surface. The more serious objection is that we should expect, on the basis of the scheme illustrated above, the excess of sodium in the cornea over that in the aqueous humour to be balanced by an equivalent deficiency of chloride and bicarbonate, as occurs in the erythrocyte, for example. It is unlikely that this 
excess of chloride is due to a non-specificity in the method of estimation; moreover, the figure presented here is in fair agreement with that given by Fischer (1933). It is possible that the thermodynamic activity co-efficients for the chloride-ion in the proteinrich cornea is much less than unity, in which case the excess of chloride 'would only be apparent.

\section{Change of Salt-Content During Storage}

After 24 hours in the ice-chest the appearance of the cornea in the excised eye has radically changed; it is no longer clear but smoky and its thickness is found to have increased quite obviously on cutting it up. Numerous experiments have been carried out by the author on the changes of water, sodium, potassium and chloride in the cornea during this ageing process; details of a single experiment agreeing substantially with all the rest will now be presented.

Eighteen fresh eyes were obtained, nine were placed in the ice-chest for 24 hours, whilst the corneae of the remainder were immediately cut up into four pieces, one for sodium determination, one for potassium, one for chloride, and one for watercontent. Since the quantities provided by a single cornea were inadequate for accurate analysis, three pieces from three separate corneae were pooled. The results therefore appeared as three determinations of each ion and of water; the mean of these three thus represented the mean of nine separate corneae. A similar procedure was adopted for the corneae from the eyes allowed to stand for 24 hours overnight.

In Table IV the results have been expressed in millimoles of ion $/ \mathrm{kg}$. of cornea. It will be noted that the mean water-content has risen from 77.3 per cent. to 82 per cent.; this is equivalent to an uptake of water of $260 \mathrm{~g} . / \mathrm{kg}$. of cornea. Sodium shows a slight decrease in concentration, potassium a larger, whilst chloride shows a slight rise. If it is appreciated that the total water-content of the cornea has increased by $260 \mathrm{~g} . / \mathrm{kg}$. of cornea, the fact that the ionic concentrations have been largely unaffected indicates that the swelling of the cornea has been associated with a migration of salt solution rather than of water alone.

We need not go into the details of the computation here, but, if allowance is made for the intra-cellular water, it appears that the total concentration of ions in the extra-cellular water falls slightly from 337 to 319 millimoles $/ \mathrm{kg}$. of water during the ageing process. Since this generally corresponds with a fall in the concentration of salts in the aqueous humour, we may conclude that the increased hydration represents predominantly a migration of aqueous humour into the cornea, and not a mere osmotic drainage of water from this fluid. It should be noted in parenthesis that the potassium content of aqueous humour may increase by 50 to 100 per cent. during a 24 hours storage of the intact eye in the ice-chest. This is presumably due mainly to loss from the 
TABLE IV

Salt contents of fresh and stored eyes in mmoles $/ \mathrm{kg}$. cornea

Fresh Eyes

\begin{tabular}{c|c|c|c|c|c}
\hline & \multicolumn{4}{|c|}{ Cornea } & \multirow{2}{*}{ Aqueous } \\
\cline { 2 - 4 } & Group I & Group II & Group III & Mean & \\
\hline $\mathrm{Na}$ & 117 & 117 & 116 & 116.7 & 147.5 \\
$\mathrm{~K}$ & 25.3 & 22.5 & 29.5 & 26 & 6.9 \\
$\mathrm{Cl}$ & 81.5 & 80.5 & 80 & -81 & 125.5 \\
$\mathrm{HCO}$ & - & - & - & 20 & 31.4 \\
$\mathrm{H}_{2} \mathrm{O}(\%)$ & 77.7 & 76.8 & 77.5 & 77.3 & 99 \\
$\begin{array}{c}\text { Total Ions } \\
\text { (mmoles/kg.) }\end{array}$ & - & - & - & 244 & 311 \\
$\begin{array}{c}\text { Total Ions } \\
\text { (mmoles/kg. } \\
\text { Extra-cellular } \\
\mathrm{H}_{2} \mathrm{O} \text { O) }\end{array}$ & - & - & - & 337 & 314 \\
& & - & & &
\end{tabular}

24-hr. Old Eyes.

\begin{tabular}{c|c|c|c|c|c}
$\mathrm{Na}^{-}$ & 116 & 115 & 115 & 115.3 & 141 \\
$\mathrm{~K}$ & 22.4 & 209 & 22.1 & 22 & 10.6 \\
$\mathrm{C} 1$ & 83.5 & 83 & 84 & 83.5 & 122.5 \\
$\mathrm{HCO}_{3}$ & - & - & - & 21 & 30.5 \\
$\mathrm{H}_{2} \mathrm{O}(\%)$ & 81.4 & 82 & 82.5 & 82 & 99 \\
$\begin{array}{c}\text { Total Ions } \\
(\text { mmoles/kg.) }\end{array}$ & - & - & - & 242 & 305 \\
$\begin{array}{c}\text { Total Ions } \\
\text { (mmoles/kg. }\end{array}$ & - & - & - & 319 & 308 \\
extra-cellular \\
\begin{tabular}{c}
$\left.\mathrm{H}_{2} \mathrm{O}\right)$ \\
\hline
\end{tabular}
\end{tabular}

cellular elements of the iris and lens; we must therefore regard with some suspicion any results on the distribution of potassium between aqueous humour and plasma derived from the studies of dead cattle eyes. It may be that some of the striking results described by Salit (1939) are attributable to this cause. 


\section{Discussion}

The results described here suggest, but of course do not prove, that the substantia propria is in approximate osmotic equilibrium with the aqueous humour; if there is any significant difference in concentration it is. rather in favour of the substantia propria than of the aqueous humour. This observation suggests, but once again does not prove, that an interchange of sodium, potassium, and chloride between aqueous humour and substantia propria is possible. This suggestion is, however, apparently ruled out by the studies of Cogan, Hirsch and Kinsey (1944) and of Holt and Cogan (1946), whose careful researches indicate that the membranes separating the substantia from the aqueous humour on the one hand, and tears on the other, are impermeable to salts although permeable to water. Whilst their results do not necessarily prove a complete absence of a transfer of salt,* we may conclude that salt exchanges are much more likely to occur between substantia propria and tissue fluid in the region of the limbus, and thence by diffusion into the axial region of the cornea. As the cornea ages, a considerable migration of salt solution into the substantia propria takes place. Thus the endothelium of the cornea permits the transfer of salts under these conditions; it is likely that this is an abnormal leakiness of the endothelium, although in view of the length of the times concerned, this transfer may be due to a normal small permeability to salts. This brings us to the problem of the normal turgescence of the cornea and its transparency. Fischer drew attention to the fact that the excised cornea placed in saline swells to a great volume; Cogan and Kinsey (1942) have emphasised this point and have drawn attention to the fact that the cornea is in contact with a saline solution at the limbus and might therefore be expected to swell by abstracting water from this region as well as from tears and aqueous humour. They developed a fluid-transfer theory of the normal maintenance of the deturgesced state of the cornea based on a turgescence at the periphery associated with a continuous abstraction of water from the more axial regions, resulting from the supposed difference of osmotic pressure between aqueous

* Complete impermeability to salts is a rare phenomenon in cells and tissues; studies with Radio-Na indicate a very slow transfer into the substantia propria through the corneal epithelium; removal of the epithelium permits a very rapid transfer into the substantia propria but migration, into the aqueous humour is impeded by the endothelium. Thus in one hour the concentration of Radio- $\mathrm{Na}$ in the aqueous humour of an ox eye, suspended in a $\mathrm{Radio}-\mathrm{Na}$ solution such that the cornea was just covered, was 0.8 per cent. of that in the outside medium. If the epithelium was stripped the result was approximately 25 per cent. It would seem that the endothelium was about 7 to 8 times more permeable to $\mathrm{Na}$ than the epithelium. It is possible, indeed probable, that degenerative changes had already occurred although the eyes were kept ice-cold during transfer from the slaughterhouse; there is no reason to believe, however, that the corneae were in any worse state than those on which permeability studies have been made in the past. 
humour and tears on the one hand, and the stroma of the cornea on the other; i.e., they assume that tears and aqueous humour are hypertonic to the stroma. This theory, attractive at first sight, runs into difficulties on near investigation. As the present results show, and as may be confirmed by numerous investigations on simpler colloidal systems, .corneal stroma, increases its watercontent by the imbibition of a saline solution and not merely of water; this follows automatically from the Donnan-Equilibrium theory of gel swelling. If, therefore, there is a continuous absorption of water at the periphery of the cornea, there must also be an absorption of salt; the abstraction of water alone from the stroma, by the supposed difference of osmotic pressure, will lead to an accumulation of salt in the stroma tending to abolish the difference of osmotic pressure necessary for the removal of water. This excess of salt would, of course, tend to diffuse back to the limbus, but it seems to the author that on kinetic grounds the osmotic mechanism, regarded as a means of maintaining the cornea in a deturgesced state, would be very inefficient-salt and water entering by flow; water leaving by flow over a large available surface and salt only by diffusion through a restricted surface. The mechanism depends, moreover, on a supposed difference of osmotic pressure between the stroma and tears, effectuated by the corneal epithelium which is impermeable to salts. Tears are said by Krogh (1945) to be isotonic with blood but this of itself is no serious objection since we may assume that their effective concentration on the surface of the cornea is considerably greater, on account of evaporation. It is known, however, that closure of the eyes for long periods, as in sleep, does not cause an oedematous condition of the cornea; moreover, stripping the corneal epithelium, thereby preventing any difference of osmotic pressure from acting, likewise does not cause any optically noticeable increase in hydration of the cornea during the 24 hours required for its regeneration.

Thus as an adequate explanation for the normal deturgesced state of the cornea, the theory of Cogan and Kinsey cannot be readily accepted; whether some modification could meet the objections raised here it is difficult to say.* In the view of the author, any theory that ignores, or attributes a minor rôle to vital activity on the part of the cellular constituents of the corneaepithelium, endothelium, corneal corpuscles-is unlikely to prove

* Attention has been drawn elsewhere (Davson, 1949), to the fact that there is no need to assume, as earlier authors have done, that there is any tendency for the stroma to absorb water from the aqueous humour and tears. Because of the impermeability of the lining membranes to salts, a Donnan swelling is impossible, in the same way that the erythrocyte does not swell up and burst although it contains a 30 per cent. solution or gel of haemoglobin; lf the membrane is made permeable to salts the Donnan swelling occurs (vide e.g.,.Davson and Ponder, 1940). Similarly the swelling described in this paper must be regarded as a result of a permeability of the endothelium to salts occurring as a degenerative change. 
fruitful. Superimposed on any physical conditions favouring a dehydration of the colloidal constituents of the substantia propria there must be an over-riding chemical control dependent on the metabolism of the cornea as a whole. The studies of Fischer, and more particularly of Cogan and Kinsey, have clarified many of the physico-chemical aspects of corneal hydration in a valuable manner; further research must follow on an exact analysis of the changes occurring under conditions of disturbed metabolism. Thus it has been shown by Pirie, Schmidt and Waters (1948), that the corneal collagen is at its swelling minimum in the physiological range of $\mathrm{pH}$, and that on the acid side of this minimum the swelling curve rises steeply. Work on the cornea has been largely carried out on the excised eye; if this is dying we must expect an increased acidity of the medium and thus a large increase in turgescence. It would be quite wrong to say that the normal cornea must possess a mechanism for preventing this, over and above the normal vegetative metabolism which preserves the physiological $\mathrm{pH}$. It should be noted that the iso-electric point of the corneal stroma, as opposed to that of collagen, is not $\mathrm{pH}$ 7.4 but on the acid side; presumably this is due to the hyaluronic acid present.

\section{Summary}

The distribution of sodium, potassium and chloride between the corneal extra-cellular water and aqueous humour in fresh and stored ox eyes has been determined. It is shown that the increased hydration of the cornea accompanying storage is associated with the migration of salts so that, in effect, aqueous humour, and not merely water, is taken up.

The results are discussed in relation to current theories of corneal transparency.

I am indebted.to Miss P. A. Matchett for carrying out many of the chemical determinations.

\section{REFERENCES}

Barber, H. H., and Kolthoff, I. M. (1928).-Jl. Amer. Chem. Soc., 1, 1625. CogAN, D. G., and Kinsey, V. E. (1942).-Arch. of Ophthal., N.Y., 28, 661.

Cogan, D. G., Hirsch, E. O., and KINSEY, E. V. (1944).-Arch.ofOphthal., N.Y., 31, 408.

Davson, H. (1939),-Jl. Physiol., 89, 61.

(1949). - The Physiology of the Eye. Churchill, London.

Davson, H. and Ponder, E. (1940).-Jl. Cell. Comp. Physiol., 15, 67.

Fischer, F. P. (1933).-Arch. f. Augenheilk., 57, 295.

HolT, M. and CogaN, D. G. (1946).-Arch. of Ophthal., N.Y., 35, 292.

Kinsey, V. E. and CogaN, D. G. (1942).-A rch. of Ophthal., N.Y., 28, 449.

KRAMER, B. (1920). -Jl. Biol. Chem., 41, 263.

Krogh, A. (1945).-Acta Physiol. Scand., 10, 88.

Pirie, A.. Schmidt, G., and Waters. J. W. (1948).-Brit. Jl. Ophthal., 32, 321.

Salit, P. W. (1939).-Biochem. Zeitschr., 301, 253.

VAN Slyke, D. D, and Sendroy, J. (1923).-Jl. Biol. Chem., 58, 523. 